\title{
Syre-base-forstyrrelser hos intensivpasienter
}

\author{
Sammendrag \\ Bakgrunn. Syre-base-forstyrrelser \\ gir et mangfold av symptomer, bidrar \\ til flerorgansvikt og fører til svekket \\ immunforsvar. Uten kjennskap til pato- \\ fysiologi og årsaksforhold er det risiko \\ for feilbehandling. Formålet med \\ denne artikkelen er å gi en oversikt \\ over syre-base-forstyrrelser hos inten- \\ sivpasienter.
}

Materiale og metode. Artikkelen er basert på et ikke-systematisk litteratursøk i PubMed, på en lærebok i intensivmedisin og klinisk erfaring.

Resultater. Syre-base-forstyrrelser kan evalueres på to måter. HendersonHasselbalchs likning beskriver syrebase-status via endringer i $p \mathrm{CO}_{2}$ og $\mathrm{HCO}_{3}{ }^{-}$. Endringer i $p \mathrm{CO}_{2}$ representerer den respiratoriske delen, endringer i bikarbonatnivået hovedsakelig den metabolske. Standard baseoverskudd beskriver den metabolske delen mer eksakt. Som supplement beregnes aniongapet. Et system basert på fysikalsk-kjemiske prinsipper beskriver tre uavhengige variabler $-p \mathrm{CO}_{2}$, svake syrer og sterk ionedifferanse. Disse tre regulerer $\mathrm{pH}$-verdien og bikarbonatkonsentrasjonen.

Fortolkning. Henderson-Hasselbalchs likning og standard baseoverskudd forteller ikke hvilke syrer eller baser som er involvert eller hvor mye hver av dem bidrar til det totale avviket. Et forhøyet aniongap angir nærvær av fremmede anioner og skiller mellom hyperkloremisk acidose og andre typer metabolsk acidose. Beregning av aniongapet er beheftet med stor usikkerhet. Den fysikalsk-kjemiske metoden beskriver hvilke ioner som er involvert, men forutsetter bruk av kompliserte likninger. Metoden er klinisk lite brukervennlig. En kombinasjon av standard baseoverskudd og beregning av aniongapet korrigert for albuminnivå gir god beskrivelse av syre-basestatus.

\section{Nils Smith-Erichsen}

nils.smith-erichsen@vikenfiber.no

Ormøybakken 5

0198 Oslo

\section{Johan Kofstad}

Holmenkollveien 80

0784 Oslo

Baard Ingvaldsen

Anestesiavdelingen

Oslo universitetssykehus, Ullevål

Det er vanlig med syre-base-forstyrrelser hos intensivpasienter. De fleste er moderate og selvbegrensende, men de kan gi patofysiologisk og diagnostisk informasjon. Alvorlige forstyrrelser resulterer $i$ et mangfold av kliniske manifestasjoner og påvirker immunsystemet i negativ retning $(1,2)$.

Metabolske syre-base-forstyrrelser forekommer hyppigere, har flere årsaker og er vanskeligere å behandle enn respiratoriske forstyrrelser. Årsaken til forstyrrelsen er viktigere for utfallet enn graden av avvik $(3,4)$. Det foreligger ingen gode epidemiologiske studier (5). Formålet med denne artikkelen er å gi en oversikt over syre-baseforstyrrelser hos intensivpasienter.

\section{Materiale og metode}

Artikkelen er basert på et ikke-systematisk litteratursøk i PubMed, på kapitler om syrebase-forhold i en intensivmedisinsk lærebok og på forfatternes kliniske erfaringer innen anestesiologi og klinisk kjemi $(3,6)$.

\section{Den normale metabolismen}

Flyktige syrer. Hvert døgn produseres det $\mathrm{i}$ kroppen ca. $15000 \mathrm{mmol} \mathrm{H}^{+}$-ekvivalenter, som skilles ut som $\mathrm{CO}_{2}$.

Organiske syrer. Dette er ketosyrer og melkesyre, som metaboliseres av lever og nyrer. Melkesyreproduksjonen utgjør ca. $1500 \mathrm{mmol} /$ døgn. $25-30 \%$ av produsert laktat metaboliseres av nyrene. Ved høyt nivå skilles laktat ut i urinen (7).

Uorganiske syrer. Svovelsyre og fosforsyre fra protein- og aminosyremetabolismen er de to viktigste uorganiske syrene, med en samlet døgnproduksjon på ca. 1,5 mmol/kg/ døgn, som skilles ut i urinen. Syrene skilles ut uavhengig av hverandre, og overskudd av én syre kompenseres ikke med økt utskilling av de andre (8).

Lungene, via respirasjonssenteret, reagerer spontant på endringer i hydrogenione- konsentrasjonen, mens nyrene bruker timer til dager $(3,6)$.

De biologiske kompensasjonsmekanismene er ufullstendige, $\mathrm{pH}$-verdien reflekterer derfor den primære årsaken $(6,8)($ tab 1). Hydrogenionekonsentrasjonen i plasma reguleres av potente mekanismer på celle- og organnivå $(3,8)$.

\section{Metodologi}

Konsentrasjon av hydrogenioner måles med den ikke-lineære logaritmiske $\mathrm{pH}$-skalaen $\left(\mathrm{pH}=-\log _{10}\left[\mathrm{H}^{+}\right] \mathrm{i} \mathrm{mol} / \mathrm{l}\right)($ tab 1) (8).

\section{Henderson-Hasselbalchs likning}

Denne likningen er det tradisjonelle utgangspunkt for vurdering av syre-base-forstyrrelser:

$$
\mathrm{CO}_{2}+\mathrm{H}_{2} \mathrm{O} \leftrightarrow \mathrm{H}_{2} \mathrm{CO}_{3} \leftrightarrow \mathrm{H}^{+}+\mathrm{HCO}_{3}^{-}
$$

Omarbeidet og i logaritmisk form får man: $\mathrm{pH}=\mathrm{pK}\left(\mathrm{H}_{2} \mathrm{CO}_{3}\right)+\log \left[\mathrm{cHCO}_{3}^{-} /\left(\mathrm{k} \cdot p \mathrm{CO}_{2}\right)\right]$ hvor $\mathrm{pK}$ er disossiasjonskonstanten for karbonsyre $\left(\mathrm{H}_{2} \mathrm{CO}_{3}\right)$ og k er løselighetskoeffisienten for $\mathrm{CO}_{2} \mathrm{i}$ plasma. $\mathrm{pH}$-verdien bestemmes av forholdet mellom $p \mathrm{CO}_{2}(\mathrm{kPa})$ og $\mathrm{cHCO}_{3}^{-} \cdot p \mathrm{CO}_{2}$ beskriver den respiratoriske delen, $\mathrm{CHCO}_{3}{ }^{-}$den metabolske. Metoden er deskriptiv og acidose/alkalose uansett årsak beskrives av $\mathrm{cHCO}_{3}{ }^{-}-p \mathrm{CO}_{2}$-ratio.

\section{Bufferbase/baseoverskudd}

Bufferbase (BB) er summen av konsentrasjonene av bikarbonat og ikke-flyktige svake syreanioner og beskriver bedre den metabolske komponenten (9). Baseoverskudd (BE) defineres som den mengde sterk syre eller base som må tilsettes fullblod in vitro for å bringe $\mathrm{pH}$-verdien tilbake til 7,4 ved $p \mathrm{CO}_{2} 5,3 \mathrm{kPa}$ og temperatur $37,0^{\circ} \mathrm{C}(10,11)$ (tab 2). Variabelen standard baseoverskudd (SBE) «fordeler» hemoglobinet over hele det ekstracellulære væskerom (hemoglobin

\section{Hovedbudskap}

- Metabolsk acidose er vanligste syrebase-forstyrrelse

- Ta en grundig anamnese

- Beregn aniongap korrigert for albuminkonsentrasjon

- Beregn osmolalt gap

- Behandle årsaken

- Korriger elektrolyttforstyrrelser

- Korriger ev. til pH 7,20-7,25 
Tabell 1 Forholdet mellom pH og hydrogenionekonsentrasjonen $(6,8)$

\begin{tabular}{|cc|}
\hline $\mathrm{pH}$ & $\left(\mathrm{H}^{+}\right) \mathrm{nmol} / \mathrm{l}$ \\
\hline 7,60 & 25 \\
\hline 7,50 & 32 \\
\hline 7,40 & 40 \\
\hline 7,30 & 50 \\
\hline 7,20 & 60 \\
\hline 7,10 & 80 \\
\hline 7,00 & 100 \\
\hline 6,90 & 125 \\
\hline 6,80 & 160 \\
\hline
\end{tabular}

$=5 \mathrm{~g} / 100 \mathrm{ml}$ ), gir bedre nøyaktighet av baseoverskudd in vivo og er mer uavhengig av $p \mathrm{CO}_{2}(6,12,13)$.

\section{Aniongap}

Aniongapet (AG) er den mengde anioner i $\mathrm{mmol} / \mathrm{l}$ som ikke rutinemessig måles i plasma. Det beregnes med følgende formel:

$\mathrm{AG}=\left(\mathrm{Na}^{+}+\mathrm{K}^{+}\right)-\left(\mathrm{Cl}^{-}+\mathrm{HCO}_{3}^{-}\right)$

Aniongapets referanseområde avhenger av sykehusets referanseverdier for de målte variablene (14). Aniongapet fylles opp av bufferanionene albumin og fosfat samt laktat og «fremmede» anioner (fig 1, fig 2) (15).

Aniongapet er i normalområdet ved hyperkloremisk acidose, hvor kloridnivået er forhøyet tilsvarende fallet i bikarbonatnivået. Ved andre typer metabolsk acidose er kloridverdien normal, bikarbonatverdien lav og aniongapet forhøyet.

Ved hypoalbuminemi alkaliniseres plasmaet, med sekundær økning av bikarbonatnivået og redusert aniongap. En halvering av albuminkonsentrasjonen fører til en økning av baseoverskuddet på ca. $6 \mathrm{mmol} / \mathrm{l}$. Ved en kombinasjon av hypoalbuminemi og metabolsk acidose kan aniongapet være innenfor normalområdet.

Aniongapet korrigeres for konsentrasjonen av albumin med følgende formel (16): $\mathrm{AG}_{\text {korrigert }}(\mathrm{mmol} / \mathrm{l})=\mathrm{AG}+0,25 \cdot[$ normalt albuminnivå - målt albuminnivå $(\mathrm{g} / \mathrm{l})]$

SBEecv fanger ikke opp den alkaliniserende effekten av hypoalbuminemi.

Stewarts fysikalsk-kjemiske metode for analyse av syre-base-status identifiserer hvilke ioner som er involvert og synliggjør nærværet av ikke-identifiserte anioner (SIG, sterkt ionegap) (fig 1, fig 2) (15). Metoden er populær hos forskere, men lite brukervennlig klinisk på grunn av kompliserte likninger og behov for programmerbar kalkulator (1). Flere har forsøkt å gjøre Stewarts metode mer brukervennlig (4, 14, 17-19). Det er god korrelasjon mellom Stewarts SIG og aniongap korrigert for hypoalbuminemi (4, $8,14,18,19)$.

\section{Metabolsk acidose}

Det er tre årsaker til denne tilstanden $(3,8)$ : - Sykdom eller svikt i regulerende organer

- Tilførsel av stoffer som metaboliseres til organiske syrer

- Så store endringer i metabolismen at normale reguleringsmekanismer svikter

Metabolsk acidose utløser en korrigerende respiratorisk alkalosekomponent. Tilstanden klassifiseres etter den aktuelle syren eller etter om det foreligger et forhøyet aniongap eller ikke. Ved forhøyet aniongap er det en økt mengde anioner fra metabolske syrer eller fremmede forgiftningssyrer.

Acidose med normalt aniongap er av hyperkloremisk type.

\section{Forhøyet aniongap-acidose (AG-acidose)}

Forhøyet AG-acidose forårsakes av tilstander som fører til opphopning av metabolske syreanioner. Hvis årsaken er uklar, beregnes osmolalt gap (OG).

$\mathrm{OG}=$ Beregnet osmolalitet $(\mathrm{BO})$ - målt osmolalitet (MO)

$\mathrm{BO}=\mathrm{Na} \cdot 2+$ glukose + urinstoff

Formelen konverterer mmol/1 til osmolalitet og korrelerer godt med målt osmolalitet hos pasienter uten osmolalitetsforstyrrelser (20, 21). Et osmolalt gap på over $20 \mathrm{mmol}$ osmoler/kg vann indikerer et betydelig nivå av fremmede osmoler i plasma, og intoksikasjon med toksiske alkoholer må mistenkes $(22,23)$.

Laktacidose assosieres med sirkulasjonssvikt og anaerob metabolisme. Laktatmetabolismen er komplisert, og økt laktatnivå er ikke alltid indikasjon på iskemi. B1-agonister i kontinuerlig infusjon stimulerer laktatproduksjonen. Laktat finnes som L- og Disomerer. L-isomeren genereres ved endogen metabolisme. D-isomeren produseres av tarmbakterier og ble tidligere tatt som ut-

Tabell 2 Primære syre-base-forstyrrelser og deres kompensasjonsmekanismer

\begin{tabular}{|c|c|c|c|c|c|c|}
\hline \multirow{2}{*}{$\begin{array}{l}\text { Primær årsak } \\
\text { Metabolsk alkalose }\end{array}$} & \multicolumn{2}{|c|}{$\begin{array}{l}\text { Primær } \\
\text { forandring }\end{array}$} & \multirow{2}{*}{$\begin{array}{l}\text { Sekundær } \\
\text { kompensasjon } \\
\text { Respiratorisk acidose }\end{array}$} & \multicolumn{2}{|c|}{$\begin{array}{l}\text { Sekundær } \\
\text { kompensasjon }\end{array}$} & \multirow{2}{*}{$\begin{array}{l}\mathrm{pH} \\
\uparrow\end{array}$} \\
\hline & $\mathrm{BE}:$ & $\uparrow$ & & $\mathrm{pCO}_{2}:$ & $\uparrow$ & \\
\hline Metabolsk acidose & $\mathrm{BE}:$ & $\downarrow$ & Respiratorisk alkalose & $\mathrm{pCO}_{2}:$ & $\downarrow$ & $\downarrow$ \\
\hline Respiratorisk acidose & $\mathrm{pCO}_{2}:$ & $\uparrow$ & Metabolsk alkalose & BE: & $\uparrow$ & $\downarrow$ \\
\hline Respiratorisk alkalose & $\mathrm{pCO}_{2}$ : & $\downarrow$ & Metabolsk acidose & BE: & $\downarrow$ & $\uparrow$ \\
\hline
\end{tabular}

trykk for tarmiskemi. Blodgassapparater måler L-isomeren (23).

Metforminindusert laktacidose er en livstruende komplikasjon til metforminbehandling av diabetes type 2. Årsaken er multifaktoriell, men kombinasjonen av metformin og behandling med ACE-hemmer er en risikofaktor $(24,25)$. Tilstanden kan gi akutt nyresvikt med behov for nyreerstattende behandling. Dialyse fjerner metforminet, som normalt skilles ut i urinen (23).

Ringer-laktat og laktatbaserte erstatningsvæsker ved nyreerstattende behandling er racemiske blandinger. Metabolismen av laktat konsumerer $\mathrm{H}^{+}$og vil sammen med $\mathrm{Na}^{+}$mengden ha en svakt alkaliniserende effekt (23). Ved bruk av laktatholdige erstatningsvæsker ved kontinuerlig nyreerstattende behandling kan man se forhøyede laktatverdier uten ledsagende acidose.

Kritisk syke med dårlig ernæringsstatus kan reagere på karbohydrattilførsel med laktacidose. Dette skyldes mangel på tiamin (vitamin $\mathrm{B}_{1}$ ), som er viktig for normal karbohydratmetabolisme. Det bør være liberale indikasjoner for substitusjonbehandling med tiamin intravenøst for denne pasientgruppen (26).

Ketoacidose skyldes $\beta$-oksidasjon av fettsyrer, en prosess som hemmes av insulin. Ved insulinmangel kan ketondanningen fra økt fettsyrenedbrytning komme ut av kontroll. Ved et blodsukkernivå over 10-12 mmol/1 oppstår det glukosuri, osmotisk diurese med polyuri, tap av kalium og hypovolemi. Dette gir økt kortisol- og katekolaminproduksjon og økt produksjon av frie fettsyrer (3). Alvorlig ketoacidose kan være første symptom på diabetes eller forekomme ved vanskelig regulerbar diabetes type 1 . Ved metabolsk acidose vandrer kalium ekstracellulært, og pasienten kan ha hyperkalemi med samtidig intracellulær kaliummangel.

Ketoner (aceteddikksyre, $\beta$-OH-smørsyre) skilles ut $\mathrm{i}$ urinen og påvises med urinstiks, som kun viser aceteddiksyre. Pasienter med hypovolemisk sirkulasjonssvikt og ketoacidose kan ha lite ketoner i urinen fordi aceteddiksyre bare produseres ved adekvat oksygentilførsel. Dette kan skape forvirring ved behandlingen - fordi flere ketoner skilles ut i urinen ved bedring av tilstanden (3, 23). Det anbefales å følge effekten av behandlingen med målinger av $\mathrm{pH}$, baseoverskudd og aniongap (3).

Diabetisk ketoacidose behandles med kontinuerlig infusjon av insulin, rikelig tilførsel av isotone elektrolyttløsninger og kaliumtilskudd. Korreksjon av acidosen med $\mathrm{NaHCO}_{3}$ er kontroversielt. Det finnes få holdepunkter for å hevde at dette er nødvendig (3).

Acidose ved intoksikasjoner skyldes forgiftning med toksiske alkoholer. Forgiftningen karakteriseres av økende metabolsk acidose på grunn av opphopning av metabolittene maursyre (metanol) og glykolsyre (etylenglykol). Metanol gir et mangfold av akutte symptomer samt nevrologiske sen- 
komplikasjoner $(23,27)$. Ved de færreste norske sykehus gjøres det hasteanalyse av metanolkonsentrasjon. Inntak av etanol og metanol øker serum-osmolaliteten og det osmolale gapet. Opphopning av maursyre og glykolsyre øker aniongapet. Bestemmelse av osmolalt gap og aniongap er derfor svært viktige diagnostiske verktøy ved slike forgiftninger (22).

Den tradisjonelle behandlingen av forgiftninger med toksiske alkoholer er infusjon av etanol som motgift, rask fullkorreksjon av acidosen (for å redusere den toksiske effekten av maursyre) og hemodialyse. Fomepizol, en alkoholdehydrogenaseinhibitor, har erstattet etanolinfusjon. I to artikler antydes det at fomepizolbehandling kan erstatte hemodialyse $(27,28)$.

\section{Acidose med normalt aniongap}

Ved tap av base $\left(\mathrm{HCO}_{3}^{-}\right)$vil hyperkloremi være sekundærkompensasjon som fører til utvikling av hyperkloremisk acidose.

Gastrointestinal hyperkloremisk acidose skyldes tap av bikarbonatholdig tarmvæske distalt for pylorus. Ved store væsketap fra tynntarm/colon er det naturlig å bruke Ringer-acetat/laktat, eventuelt isotont natriumbikarbonat som erstatningsvæske.

Behandling av hypoperfusjonssyndromer med fysiologisk saltvann $(\mathrm{NaCl} 154 \mathrm{mmol} / \mathrm{l})$ eller kunstige kolloider løst i fysiologisk eller hypertont saltvann kan gi hyperkloremisk acidose som bivirkning. Dette har liten klinisk betydning, men kan skape diagnostisk forvirring (23).

\section{Korreksjon av metabolsk acidose}

Bruk av buffere ved alvorlig metabolsk acidose er vanlig, men det er uenighet om indikasjoner og fordeler $(29,30)$.

Bufring med natriumbikarbonat genererer $\mathrm{CO}_{2}$. Dette kan ha konsekvenser for pasienter med begrenset respiratorisk reserve og for dem med alvorlig sirkulasjonssvikt. Hos disse kan det oppstå en paradoksal intracellulær acidose hvis stigningen i $p \mathrm{CO}_{2}$ overstiger stigningen i bikarbonatkonsentrasjon (30).

Det er ikke vist noen sikker klinisk effekt av bufring med natriumbikarbonat ved laktacidose og ketoacidose. Morris \& Low anbefaler forsiktig bufring med natriumbikarbonat til $\mathrm{pH} 7,20-7,25$, da overdosering kan gi intracellulær acidose, hjertesvikt, hypernatremi, redusert ionisert kalsium og volumoverbelastning (23). Senere, når pasienten metaboliserer syreoverskuddet, kan det oppstå en sekundær iatrogen metabolsk alkalose $(23,30)$.

Nyreerstattende behandling er aktuelt ved alvorlig metabolsk acidose forårsaket av visse toksiner, deres metabolitter og enkelte medikamenter. Tradisjonell intermitterende dialyse er mest effektivt, da kontinuerlige teknikker innebærer dårligere clearance. Ved sirkulatorisk instabilitet kan kontinuerlige teknikker være indisert (31).

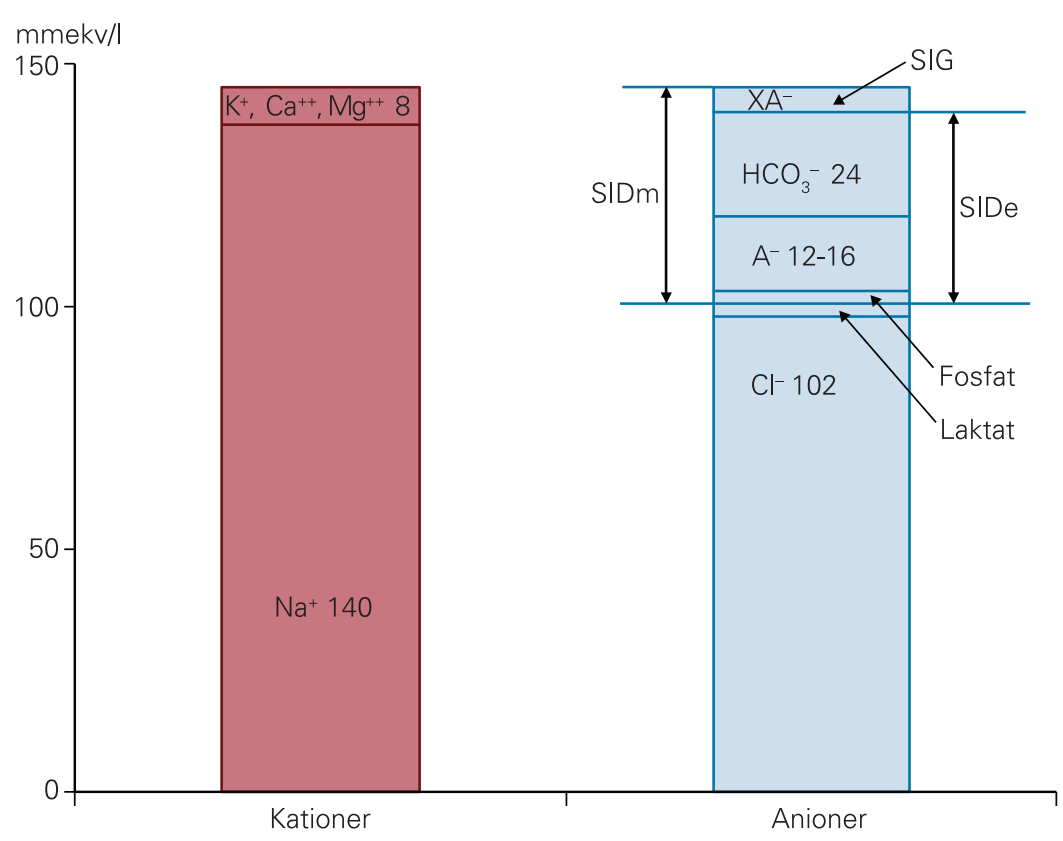

Figur 1 Gamble-diagram med oversikt over involverte ioner og deres betydning for syre-basebalansen. SID: Sterk ionedifferanse. SIG: Sterkt ionegap. SIDe: Effektiv SID lbikarbonat, albumin,

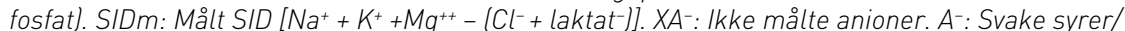
proteiner. $\mathrm{HCO}_{3}^{-}$: Bikarbonat. Differansen mellom SIDm og SIDe skal normalt være 0. Enhver differanse mellom SIDm og SIDe indikerer nærvær av fremmede anioner SIG

\section{Metabolsk alkalose}

Denne tilstanden oppstår vanligvis på grunn av tap av $\mathrm{Cl}^{-}$(fig 1). Metabolsk alkalose inndeles i:

- Kloridresponsiv, hvor kloridtapet er temporært og tilførsel av klorid erstatter det

- Kloridresistent, hvor hormonelle mekanismer eller medfødte lidelser forårsaker et kontinuerlig kloridtap som i beste fall forbigående lar seg korrigere av kloridtilførsel (3)

Hypokalemi er et konstant trekk ved metabolsk alkalose og skyldes en kombinasjon av eksterne tap og intracelluær translokasjon av kalium.

\section{Kloridresponsiv metabolsk alkalose}

Kloridresponsiv metabolsk alkalose skyldes tap av $\mathrm{Cl}^{-}$fra ventrikkelen ved oppkast eller drenasje via ventrikkelsonde. Tilstanden medfører samtidig tap av kalium og hypovolemi på grunn av væsketapet. Hypovolemi stimulerer sekresjon av aldosteron, som fører til reabsorpsjon av $\mathrm{Na}^{+}$og tap av $\mathrm{K}^{+}$og $\mathrm{Cl}^{-} \mathrm{i}$ urinen. Behandlingen er å erstatte $\mathrm{Cl}^{-}$tapet (3).

Dette gjøres ved intravenøs tilførsel av $0,9 \% \mathrm{NaCl}$ og $\mathrm{KCl}$. I sjeldne tilfeller hvor hypokalemi eller hypovolemi ikke er noe problem, kan kloridtapet erstattes med fortynnet saltsyre (3).

Ved intens bruk av tiaziddiuretika hos pasienter med hjertesvikt skilles natrium, kalium, klorid og vann ut i urinen. Dette fører til intravasal hypovolemi. Tapene fremmer utviklingen av metabolsk alkalose. Hypovolemi stimulerer sekresjonen av renin og aldosteron, som demper natriumtapet, men øker utskillingen av kalium og hydrogenioner i urinen. Hypokalemi stimulerer reabsorpsjon av bikarbonat i proksimale tubuli og produksjon av ammonium, noe som øker utskillingen av syre i urinen (paradoks aciduri) (32). Behandlingen består av tilførsel av ikke-natriumholdige kloridløsninger, (kalium-/ammoniumklorid). Selv ved hypovolemi vil tilførsel av klorid indusere bikarbonaturi og korreksjon av alkalosen (32).

\section{Stewarts uavhengige variabler}

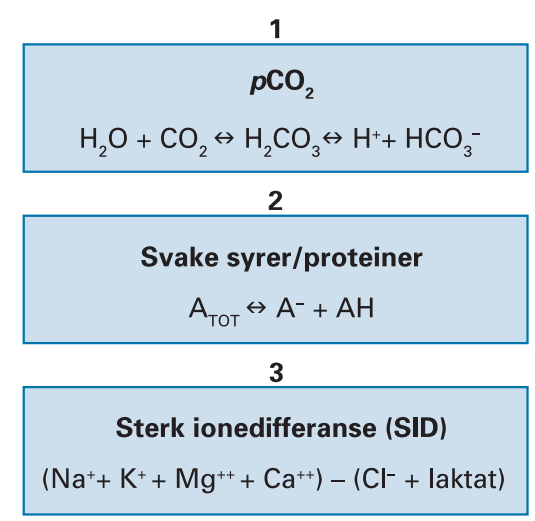

Figur 2 Stewarts tre uavhengige variabler som kontrollerer pH (15) 
Andre årsaker til metabolsk alkalose

Ved massive transfusjoner oppstår det $i$ etterkant en metabolsk alkalose. Årsaken er at natriumsitrat brukes som antikoagulasjonsmiddel. $\mathrm{Na}^{+}$, et sterkt kation, gis sammen med sitrat, et svakt anion. Når sitrat metaboliseres, konsumeres $\mathrm{H}^{+}$. Dette gir sterkt økt ionedifferanse (SID) og alkalose. Det samme kan man se ved bruk av enkelte parenterale ernæringsløsninger der det er overskudd av acetat (svakt anion) og ikke nok $\mathrm{Cl}^{-}$til å balansere $\mathrm{Na}^{+}$-mengden (3).

\section{Respiratoriske syre-base-forstyrrelser}

Disse forstyrrelsene er enklere å diagnostisere og behandle enn de metabolske. Den alveolære ventilasjonen styres av respirasjonssenteret etter respons på endringer $\mathrm{i}$ $\mathrm{CO}_{2}$-produksjon, $\mathrm{pH}, \mathrm{paO}_{2}$, fysisk aktivitet, angst og enkelte andre signaler for å holde arteriell $p \mathrm{CO}_{2}$ mellom $4,6 \mathrm{kPa}$ og $6 \mathrm{kPa}$ (3).

Når den alveolære ventilasjonen er økt eller redusert i forhold til $\mathrm{CO}_{2}$-produksjonen, har man en respiratorisk syre-base-forstyrrelse (3).

\section{Respiratorisk acidose}

Respiratorisk acidose oppstår når eliminasjonen av $\mathrm{CO}_{2}$ ikke holder tritt med $\mathrm{CO}_{2}$ produksjonen (alveolær hypoventilasjon). Alveolær hypoventilasjon har mange årsaker - økt dødromsventilasjon, luftveisobstruksjon, thoraxskader, kyfoskoliose, nevrologiske sykdommer, muskelsykdommer, redusert bevissthet (intoksikasjoner), akutt lungesvikt-syndrom og annen akutt alvorlig sykdom.

$p \mathrm{CO}_{2}$ stiger inntil ny likevekt mellom den alveolære ventilasjonen og $\mathrm{CO}_{2}$-produksjonen er oppnådd. Når den alveolære $p \mathrm{CO}_{2}$ stiger, fortrenges oksygen fra alveolene og risikoen for hypoksi øker, spesielt ved luftventilasjon. Vevsacidose forekommer alltid - fordi $\mathrm{CO}_{2}$ akkumuleres i vevet. Vedvarer tilstanden, vil det utvikles renal kompensasjon ved at $\mathrm{Cl}^{-}$blir eliminert og erstattet med bikarbonat. Pasienter med nyresvikt kan ha problemer med å kompensere kronisk respiratorisk acidose (3).

Spørsmål om respiratorbehandling ved kronisk obstruktiv lungesykdom (kols) med akutt eksaserbasjon kan være vanskelig. Grundig anamnese med detaljerte spørsmål om funksjonsnivå er svært viktig. Respiratorinnstillingene bør tilstrebe pasientens daglige $p \mathrm{CO}_{2}$-nivå. En for høy ventilasjon som senker pasientens $p \mathrm{CO}_{2}$, fører til en betydelig kombinert respiratorisk og metabolsk alkalose. Ved avansert sykdom kan det være svært problematisk å avvenne pasienten fra respiratoren. Ikke-invasiv ventilasjonsstøtte er å foretrekke.

\section{Respiratorisk alkalose}

Patologisk respiratorisk alkalose forekommer i tidlig fase av akutt lungesvikt-syn- drom, tidlig i forløpet av alvorlig sepsis, ved leversvikt og ved salisylatintoksikasjon. Man må se respiratorisk alkalose som et symptom på underliggende sykdom (3).

\section{Oppgitte interessekonflikter: Ingen}

\section{Litteratur}

1. Kellum JA. Disorders of acid-base balance. Crit Care Med 2007; 35: 2630-6.

2. Kellum JA, Song M, Li J. Science review: extracel lular acidosis and the immun response: clinical and physiological implications. Crit Care 2004; 8 $331-6$.

3. Kellum JA. Diagnosis and treatment of acid-base disorders. I: Grenvik A, Ayres SM, Holbrook PR et al, red. Textbook of critical care. Philadelphia, PA WB Saunders, 2000: 839-53.

4. Moviat M, van Haren F, van der Hoeven H. Conven tional or physiochemical approach in intensive care unit patients with metabolic acidosis. Crit Care 2003: 7: R41-R45.

5. Gunnerson KJ. Clinical review: the meaning of acid-base abnormalities in the intensive care unit - epidemiology. Crit Care 2005; 9: 508-16.

6. Schlichtig R. Acid-base balance (quantitation]. 1. Grenvik A, Ayres SM, Holbrook PR et al, red. Textbook of critical care. Philadelphia, PA: WB Saunders, 2000: 828-39

7. Bellomo R. Bench-to-beside review: lactate and the kidney. Crit Care 2002; 6: 322-6.

8. Morris CG, Low J. Metabolic acidosis in the critically ill: part 1. Classification and pathophysiology. Anaesthesia 2008; 63: 294-301

9. Singer RB, Hastings AB. An improved clinical method for the estimation of disturbances of the acid-base balance of human blood. Medicine (Baltimore) 1948; 27: 223-42.

10. Astrup P, Jørgensen K, Siggaard-Andersen 0 . Acid-base metabolism: new approach. Lancet 1960: 1: 1035-9

11. Siggaard-Andersen 0 . The $\mathrm{pH}$-log PCO2 blood acid-base nomogram revised. Scand J Clin Lab Invest 1962; 14: 598-604

12. Schlichtig R, Grogono A, Severinghaus JW. Human $\mathrm{PaCO} 2$ and standard base excess compensation for acid-base imbalance. Crit Care Med 1998; 26 : 1173-9.

13. Kofstad J. Historikk. I: Kofstad J. Blodgasser elektrolytter og hemogobin - metode og klinikk. Oslo: Tano Aschehoug, 2003: 9-14.

14. Kellum JA. Clinical review: reunification of acidbase physiology. Crit Care 2005; 9: 500-7.

15. Stewart PA. Modern quantitative acid-base chemistry. Can J Physiol Pharmacol 1983; 61 . 1444-61.

16. Figge J, Jabor A, Kazda A et al. Anion gap and hypoalbuminemia. Crit Care Med 1998; 26: 1807-10.

17. Fencl V, Jabor A, Kazda A et al. Diagnosis of metabolic acid-base disturbances in critically ill patients. Am J Respire Crit Care Med 2000; 162 $2446-51$

18. Dubin A, Menises MM, Masevicius FD et al. Comparison of three different methods of evaluation of metabolic acid-base disorders. Crit Care Med 2007; 35: $1264-70$.

19. Story DA, Morimatsu H, Bellomo R. Strong ions, weak acids and base excess: a simplified FenclStewart approach to clinical acid-base disorders. Br J Anaesth 2004; 92: 54-60.

20. Worthley LI, GuerinM, Pain RW. For calculating osmolality, the simplest formula is the best. Anaesth Intensive Care 1987: 15: 199-202.

21. Kofstad J. Fysiologi. I: Kofstad J. Blodgasser, elek trolytter og hemoglobin. Oslo: Tano Aschehoug, 2003: 27-52.

22. Hovda KE, Hunderi $\mathrm{OH}$, Rudberg $\mathrm{N}$ et al. Anion and osmolal gaps in the diagnosis of methanol poisoning: clinical study in 28 patients. Intensive Care Med 2004; 30: 1842-6.

23. Morris CG, Low J. Metabolic acidosis in the critically ill: part 2. Causes and treatment. Anaesthesia 2008; 63: 396-411.

24. Gudmundsdottir H, Aksnes H, Heldal Ket al. Metformin and antihypertensive therapy with drugs blocking the renin angiotensin system, a cause of concern? Clin Nephrol 2006; 66: 380-5

25. Galea M, Jelacin N, Bramham Ket al. Severe lactic acidosis and rhabdomyolysis following metformin and ramipril overdose. $\mathrm{Br} J$ Anaesth 2007. 98 : $213-5$

26. Corcoran TB, O'Hare B, Phelan D. Shoshin BeriBeri precipitaded by intravenous glucose. Critical Care and Resuscitation 2002; 4: 31-4

27. Mégarbane B, Borron SW, Baud FJ. Current recommendations for treatment of severe toxic alcohol poisonings. Intensive Care Med 2005; 31 : 189-95.

28. Hovda KE, Jacobsen D. Expert opinion: fomepizole may ameliorate the need for hemodialysis in methanol poisoning. Hum Exp Toxicol 2008; 27 : $539-46$.

29. Kraut JA, Kurtz I. Use of base in the treatment of acute severe organic acidosis by nephrologists and critical care physicians: results of an online survey. Clin Exp Nephrol 2006; 10: 111-7.

30. Gelbach BK, Schmidt GA. Bench-to-bedside review: treating acid-base abnormalities in the intensive care unit - the role of buffers. Crit Care 2004; 8: 259-65.

31. Goodman JW, Goldfarb DS. The role of continuous renal replacement therapy in the treatment of poisoning. Semin Dial 2006: 19: 402-7.

32. Galla JH. Metabolic alkalosis. J Am Soc Nephrol $2000 ; 11: 369-75$

Manuskriptet ble mottatt 28.2. 2010 og godkjent 27.5. 2010. Medisinsk redaktør Are Brean. 